\title{
A DISPONIBILIDADE HÍDRICA DAS LAGOAS JIQUI E PIUM E O CARÁTER LOCAL EFLUENTE EM RELAÇÃO AO AQUÍFERO BARREIRAS - LITORAL SUL DE NATAL - RN
}

\author{
Leandson Roberto Fernandes de Lucena ${ }^{1,2}$, Joana D’Arc Freire Medeiros ${ }^{1}$, \\ Nelson Césio Fernandes Santos ${ }^{1}$
}

\begin{abstract}
RESUMO O presente artigo representa uma síntese parcial dos resultados de pesquisa executada pela Fundação NorteRio-Grandense de Pesquisa e Cultura-FUNPEC para a Companhia de Águas e Esgotos do Rio Grande do Norte-CAERN, desenvolvida no setor oriental da bacia do Rio Pirangi. A mesma objetivou avaliar a disponibilidade hídrica das lagoas do Jiqui e Pium, bem como suas relações com o Aqüífero Barreiras, com vistas a possibilitar um incremento do abastecimento d'água da zona sul de Natal e Parnamirim-RN. A metodologia adotada foi fundamentada no emprego conjunto de técnicas de hidrogeologia e hidrologia. A análise da superfície potenciométrica do Aqüífero Barreiras evidenciou a existência de duas zonas de recarga, a primeira situada na área da sede municipal de Parnamirim e a segunda a norte do Sistema Lacustre do Bonfim (Nísia Floresta-RN). Já a zona de descarga regional localiza-se na área da Lagoa do Jiqui, baixo curso do Rio Pitimbu e Riacho Taborda, ressaltando-se o caráter efluente do contexto hidrológico supeficial. O modelagem hidrológica da Lagoa do Jiqui revelou uma disponibilidade da ordem de $2.100 \mathrm{~m}^{3} / \mathrm{h}$. Este valor, somado aos cinco poços locais operacionais e dois outros propostos elevarão a disponibilidade d'água do Sistema Jiqui para cerca de $2.800 \mathrm{~m}^{3} / \mathrm{h}$. A Lagoa do Pium revelou uma disponibilidade da ordem de $1.000 \mathrm{~m}^{3} / \mathrm{h}$.
\end{abstract}

Palavras-chave: Lagoas Jiqui e Pium; modelagem hidrológica; Aqüífero Barreiras

\begin{abstract}
The present article represents a partial synthesis of the results of a research executed by the Foundation North-Rio-Grandense of Research and Culture-FUNPEC for the Company of Waters and Sewers of Rio Grande do Norte StateCAERN, developed in the oriental section of the Pirangi River basin. The main purpose is to evaluate the water readiness of the Jiqui and Pium Lagoons, as well as your relationships with Barreiras Aquifer, to make possible an increment of the water supply of the south zone of Natal City and Parnamirim-RN. The adopted methodology was based in the united employment of hydrogeology and hydrology techniques. Potenciometric surface of Barreiras Aquifer evidenced two recharge zones, located in the area of the municipal seat of Parnamirim and north of the Bonfim Lacustrine System (Nísia Floresta-RN). The zone of regional discharge is already located in the area of the Jiqui Lagoon and low course of Pitimbu River and Taborda Brook, being pointed out the effluent character of the hydrological superficial context. The hydrological modelling of the Jiqui Lagoon revealed a readiness of the order of $2100 \mathrm{~m}^{3} / \mathrm{h}$. This value, added to the five operational local wells and two other proposed they will elevate the readiness of water of the Jiqui System for about $2800 \mathrm{~m}^{3} / \mathrm{h}$. the Pium Lagoon revealed a readiness of the order of $1000 \mathrm{~m}^{3} / \mathrm{h}$.
\end{abstract}

Keywords: Jiqui and Pium Lagoons; hydrological modeling, Barreiras Aquifer

\section{INTRODUÇÃO E OBJETIVOS}

A Companhia de Águas e Esgotos do Rio Grande do Norte-CAERN vem enfrentando ultimamente um crescente quadro de contaminação por nitrato em poços das captações destinadas ao abastecimento de Parnamirim-RN e a Zona Sul da capital Natal. Face a esta problemática, buscam-se alternativas para novas captações que venham a atender o aumento natural da demanda, além de possibilitar a diluição local de teores de nitrato elevados em alguns poços produtores, enquanto não se consegue soluções definitivas para conter os referidos casos de contaminação (conclusão de um programa de saneamento básico, p.ex.). Dessa forma, a área de estudo compreendeu parte do setor oriental da bacia do Rio Pirangi, situada no litoral sul de Natal-RN (Figura 1).

Nesse contexto, o presente estudo objetivou evidenciar alternativas na melhoria quantitativa e qualitativa do abastecimento público, destacandose uma avaliação consubstanciada da disponibilidade hídrica das lagoas do Jiqui (considerando um aumento de sua captação) e Pium (execução futura de um novo sistema adutor), através de modelagem hidrológica das sub-bacias Jiqui e Pium (bacia do Rio Pirangi). Somado a isso, elaborou-se o mapa potenciométrico local do Aqüífero Barreiras, com vistas a definir suas potencialidades e evidenciar a sua relação com o contexto hidrológico superficial.

\footnotetext{
${ }^{1}$ Empresa de Pesquisa Agropecuária do Rio Grande do Norte-EMPARN

${ }^{2}$ Fundação Norte-Rio-Riograndense de Pesquisa e Cultura-FUNPEC
} 


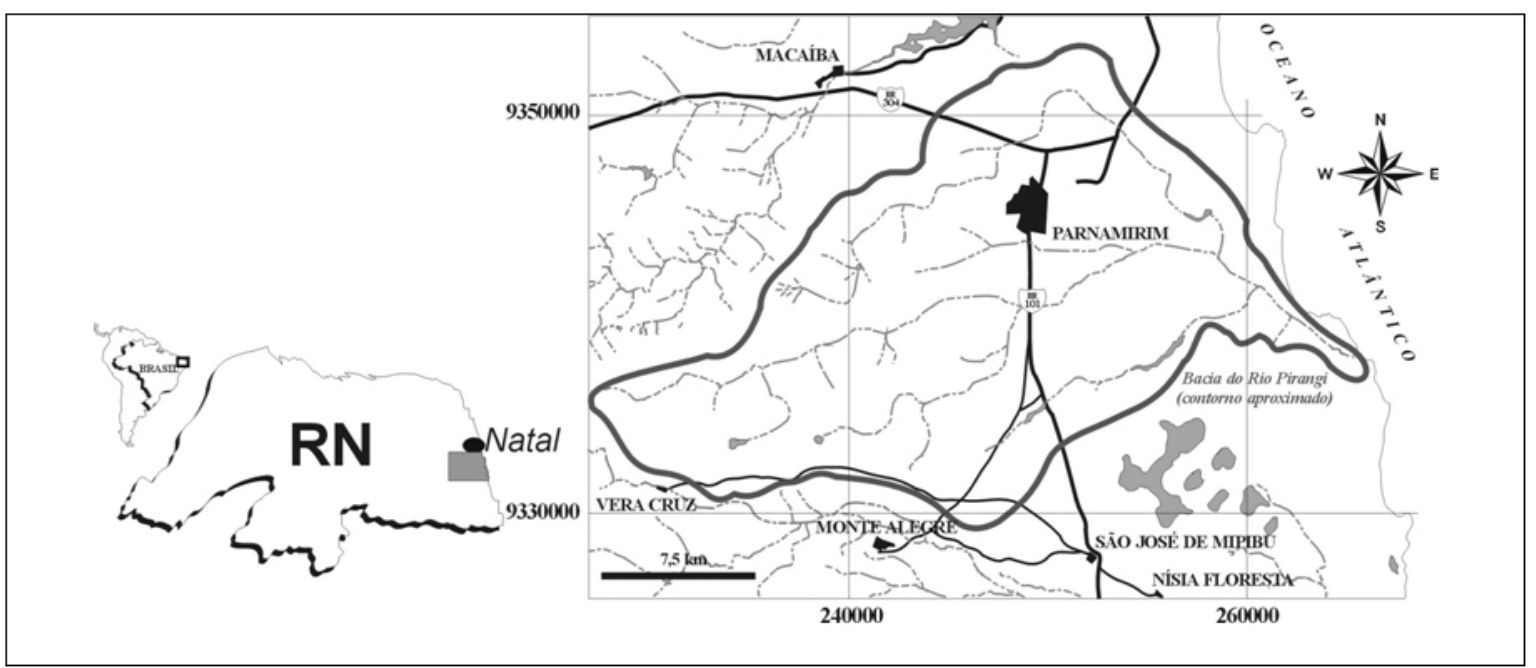

Figura 1 - Localização da área de estudo.

Figure 1 - Study area location map.

A metodologia geral adotada fundamentouse na aplicação de estudos multidisciplinares, particularmente conceitos e técnicas de hidrogeologia (potenciometria) e hidrologia (hidrometria e modelagem hidrológica).

\section{CONTEXTO HIDROLÓGICO - SUBTERRÂ- NEO E SUPERFICIAL}

\section{Potenciometria do Aqüifero Barreiras na área de estudo \\ Caracterização Geral \\ O Aqüífero Barreiras é responsável pelo} abastecimento da maioria das cidades da faixa litorânea oriental do Rio Grande do Norte, incluindo a capital Natal. O limite inferior deste aqüífero é o topo da seqüência carbonática mesozóica, não aflorante da região, a qual foi individualizada nas perfurações como sendo constituído por sedimentos areno-argilosos a argilosos de composição calcífera e baixa potencialidade hidrogeológica, ou mesmo o embasamento cristalino, nas áreas próximas do contato deste último com a bacia sedimentar costeira (Lucena e Queiroz, 1996). O aqüífero Barreiras apresenta vazões de exploração elevadas em determinadas localidades, sobretudo naquelas de maior espessura dos sedimentos do Grupo Barreiras, conforme observado em algumas captações na região sul de Natal e Parnamirim-RN (vazões da ordem de 100 $\mathrm{m}^{3} / \mathrm{h}$ ). Por outro lado, valores reduzidos de vazões explotadas são atribuídos a causas diversas, dentre as quais espessuras reduzidas da unidade e a forma de construção e desenvolvimento de poços mais antigos, face às atuais técnicas de perfuração. Um estudo realizado pelo IPT (1982) para o Governo do Estado, revelou transmissividades da ordem de $2,8 \times 10^{-3}$ a $9,2 \times 10^{-3} \mathrm{~m}^{2} / \mathrm{s}$ para a região compreendida entre Natal e São José de MipibúRN.

No tocante à condição hidrodinâmica, o Aqüífero Barreiras comporta-se de maneira bastante variável, sobretudo na região sul de Natal até a fronteira com a Paraíba. Este comportamento pode apresentar-se de livre a semiconfinado, onde a camada semiconfinante no topo, quando presente, é representada por lentes argilosas do Grupo Barreiras, (IPT, 1982).

\section{A Potenciometria Regional}

O mapa potenciométrico do setor oriental da Bacia do Rio Pirangi (Figura 2), adaptado de Lucena et al. (2004), evidenciou duas zonas de recarga, a partir das quais se originam as principais frentes de escoamento subterrâneo. A primeira situa-se na altura da cidade de Parnamirim, fato que denota alguma preocupação face às condições ainda deficitárias de saneamento básico na cidade e disposição de resíduos sólidos. A outra grande zona de recarga provém do Sistema Lacustre do Bonfim (Nísia Floresta-RN), constituindo-se num aspecto bastante relevante e confirmando em levantamento realizado por Lucena et al. (2002), 


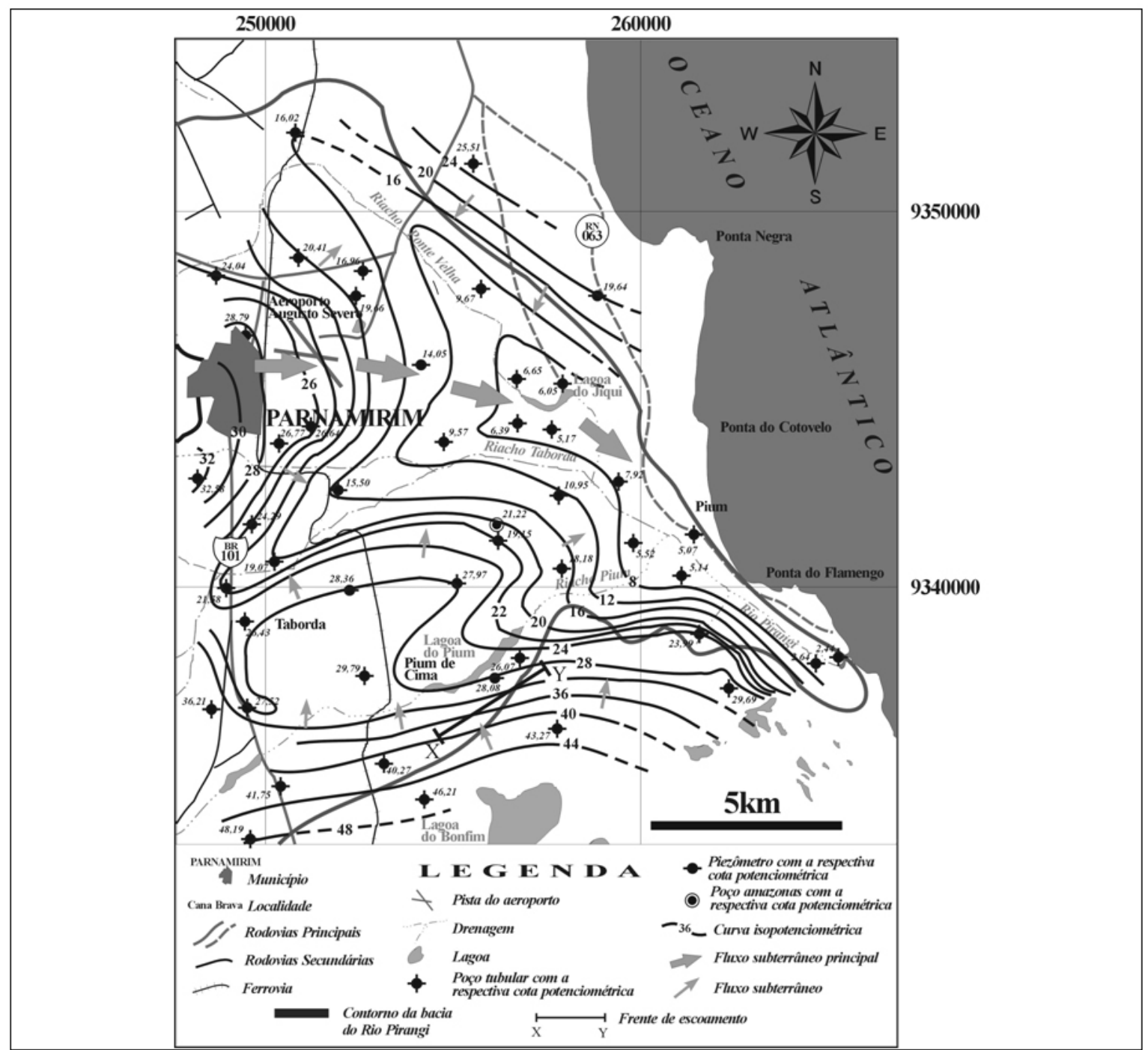

Figura 2 - Potenciometria do Aqüífero Barreiras no setor oriental da bacia do Rio Pirangi, adaptado de Lucena et al. (2004).

Figure 2 - Barreira Aquifer potenciometric map (oriental sector of Pirangi River basin), adapted from Lucena et al, (2004)

que avaliou a relação entre este sistema lacustre e a bacia do Rio Pirangi. Tal importância resulta do fato de que estudos prévios realizados na área da na área da Lagoa do Bonfim (Costa, 1997), destinados ao conhecimento da disponibilidade hídrica desta área, tendo em vista o sistema de adução Agreste-Trairi do Governo do Estado, não mostraram esta conexão hidráulica. O sistema do Bonfim, até então considerado como praticamente endorrêico, sob o ponto de vista subterrâneo, deve ser reavaliado, principalmente o contexto geológico do limite com a bacia do Pirangi e as respectivas conexões hidráulicas entre os dois sistemas.

A grande zona de descarga abrange o "binômio" Rio Pitimbu - Taborda/Pirangi, incluindo a Lagoa do Jiqui. Esta observação eleva-se em importância, a exemplo da área de recarga de Parnamirim, uma vez que a referida lagoa abastece boa parte da zona sul de Natal, devendo, portanto, receber especial atenção no tocante às suas margens e contexto subterrâneo adjacente, principalmente em termos qualitativos (monitoramento da qualidade da água de poços nas vizinhanças, por exemplo). Outra observação, não menos importante, diz respeito ao considerável espaçamento entre as isopiezas em determinados locais, refletindo baixos gradientes hidráulicos (da ordem de $10^{-3}$ ), favorecendo as condições de recarga, enquanto que valores relativamente elevados são mostrados nas áreas de descarga do aqǘfero, sobretudo no baixo curso do Rio Pirangi (gradientes hidráulicos da ordem de $\left.10^{-2}\right)$. 


\section{A BACIA DO RIO PIRANGI E AS LAGOAS DO JIQUI E PIUM}

\section{Caracterização Geral}

A bacia hidrográfica do Rio Pirangi localizase inteiramente na mesoregião Litoral Leste do Estado do Rio Grande do Norte. A mesma possui uma área total de aproximadamente $430 \mathrm{~km}^{2}$, sendo que o presente estudo concentrou-se entre a BR-101 e a linha de costa (cerca de $200 \mathrm{~km}^{2}$ ). $\mathrm{O}$ índice pluviométrico relativamente elevado (da ordem de 1562,6 mm/ano em média para o setor oriental, tomando como referência a estação meteorológica de Natal), associado ao fato da bacia estar esculpida totalmente em sedimentos do Grupo Barreiras (considerando o aqüífero predominantemente influente), origina um sistema de drenagens perenes em praticamente toda sua extensão. O Rio Pirangi nasce da confluência dos três principais tributários da bacia, riachos Taborda-Mendes, Pium e Rio Pitimbu, na altura da localidade de Pium, indo desaguar na praia homônima após um percurso de $6 \mathrm{~km}$.

\section{Dados Fluviométricos}

O acervo de dados fluviométricos na região é bastante escasso, registrando apenas cinco estações fluviométricas no litoral leste do Estado, embora nenhuma delas na bacia hidrográfica do Rio Pirangi.

Diante deste contexto de escassez de dados fluviométricos, foram selecionadas, com base em critérios hidráulicos e geométricos, 04 (quatro) seções fluviométricas de monitoramento de vazão, montante e jusante das lagoas do Jiqui e Pium (Figura 3). Os dados do monitoramento somados a outros já disponíveis (Lucena, 2005), vieram a subsidiar a avaliação das disponibilidades das referidas lagoas. A Tabela 1 apresenta os valores de vazão obtidos no presente estudo e a Tabela 2 os dados do monitoramento fluviométrico realizado por Lucena (2005).

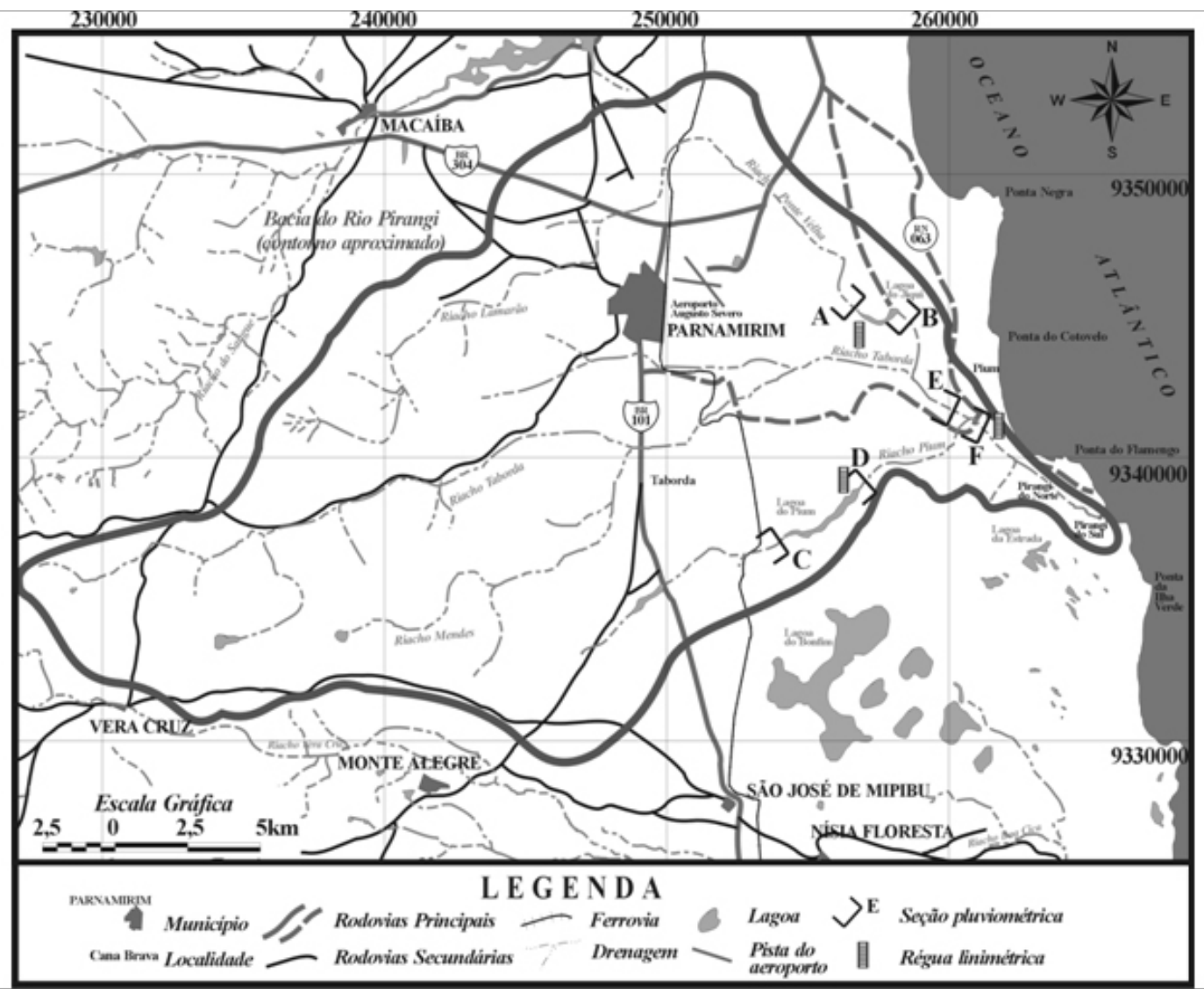

Figura 3 - Localização das estações fluviométricas.

Figure 3 -Location of fluviometric section cross. 
Tabela 1 - Vazões medidas na bacia do rio Pirangi, período 2007-2008.

Table 1 - Discharge measured on the Pirangi River basin, period 2007-2008.

\begin{tabular}{|c|c|c|c|c|c|c|c|}
\hline DIA & $\begin{array}{c}\text { Entrada } \\
\text { Lagoa } \\
\text { Jiqui }\end{array}$ & DIA & $\begin{array}{c}\text { Saída } \\
\text { Lagoa } \\
\text { Jiqui }\end{array}$ & DIA & $\begin{array}{c}\text { Entrada } \\
\text { Lagoa } \\
\text { Pium }\end{array}$ & DIA & $\begin{array}{c}\text { Saída } \\
\text { Lagoa } \\
\text { Pium }\end{array}$ \\
\hline $\mathbf{1 1 / 0 5 / 2 0 0 7}$ & 1,1697 & & & $26 / 04 / 2007$ & 0,2368 & $04 / 05 / 2007$ & 0,6062 \\
\hline $\mathbf{0 6 / 0 6 / 2 0 0 7}$ & 1,6370 & $06 / 06 / 2007$ & 1,5969 & $08 / 06 / 2007$ & 0,1307 & $08 / 06 / 2007$ & 0,5533 \\
\hline $\mathbf{1 0 / 0 7 / 2 0 0 7}$ & 1,6679 & $12 / 07 / 2007$ & 1,6947 & $12 / 07 / 2007$ & 0,2132 & $11 / 07 / 2007$ & 0,7490 \\
\hline $\mathbf{0 2 / 1 0 / 2 0 0 7}$ & 1,3637 & $02 / 10 / 2007$ & 1,1174 & $01 / 10 / 2007$ & 0,1981 & $02 / 10 / 2007$ & 0,5650 \\
\hline $\mathbf{2 4 / 0 2 / 2 0 0 8}$ & 0,6749 & $24 / 02 / 2008$ & 0,3426 & $02 / 10 / 2007$ & 0,1812 & $23 / 02 / 2008$ & 0,3073 \\
\hline $\mathbf{1 7 / 0 3 / 2 0 0 8}$ & 0,6979 & $17 / 03 / 2008$ & 0,3902 & $22 / 02 / 2008$ & 0,1208 & $17 / 03 / 2008$ & 0,4859 \\
\hline
\end{tabular}

Tabela 2 - Vazões medidas no setor oriental da bacia do Rio Pirangi no período 2000-2001 (Lucena, 2005).

Table 2 - Discharge measured on the oriental sector of Pirangi River basin, period 2000-2001 (Lucena, 2005).

\begin{tabular}{|c|c|c|c|c|c|c|}
\hline \multirow[b]{2}{*}{$\begin{array}{c}\text { MED. MENSAIS } \\
\text { Q }\left(\mathrm{m}^{3} / \mathbf{s}\right)\end{array}$} & \multicolumn{6}{|c|}{ ESTAÇÕES FLUVIOMÉTRICAS } \\
\hline & $\begin{array}{c}\text { Rio Pitimbu } \\
\text { (in Lagoa } \\
\text { Jiqui)-A }\end{array}$ & $\begin{array}{c}\text { Rio Pitimbu } \\
\text { (out Lagoa } \\
\text { Jiqui)-B }\end{array}$ & $\begin{array}{c}\text { Rch. Pium } \\
\text { (in Lagoa } \\
\text { Pium)-C }\end{array}$ & $\begin{array}{c}\text { Rch. Pium } \\
\text { (out Lagoa } \\
\text { Pium)-D }\end{array}$ & $\begin{array}{c}\text { Rch. } \\
\text { Taborda- } \\
\text { E } \\
\end{array}$ & $\begin{array}{c}\text { Rio } \\
\text { Pirangi- } \\
\text { F }\end{array}$ \\
\hline FEV/2000 & - & - & - & - & 1,0186 & 1,3705 \\
\hline MAR/2000 & 0,4267 & - & 0,0784 & 0,3085 & 0,8328 & 1,1409 \\
\hline $\mathrm{ABR} / \mathbf{2 0 0 0}$ & 0,7486 & 0,3226 & 0,1258 & 0,4290 & 1,6597 & 2,2908 \\
\hline MAI/2000 & 0,8054 & 0,4820 & 0,1429 & 0,2021 & 1,9496 & 2,5576 \\
\hline JUN/2000 & 3,3254 & 3,2569 & 0,1678 & 0,8336 & - & - \\
\hline JUL/2000 & 3,0253 & - & 0,2501 & 1,0839 & - & 6,9656 \\
\hline AGO/2000 & 2,8795 & 2,6549 & 0,3420 & 1,4226 & 5,3040 & 7,8391 \\
\hline SET/2000 & 3,3387 & 3,1438 & 0,4017 & 1,2336 & 4,4212 & 7,5157 \\
\hline OUT/2000 & 2,4768 & 2,2181 & 0,3896 & 1,0702 & 4,1373 & 5,5374 \\
\hline $\mathrm{NOV} / 2000$ & 2,3982 & 2,0076 & 0,3605 & 1,0362 & 3,5197 & 5,4746 \\
\hline DEZ/2000 & 2,06874 & 1,82837 & 0,32799 & 0,92808 & 3,12841 & 4,92328 \\
\hline MAR/2001 & 2,02583 & 1,48393 & 0,31107 & 1,17835 & 3,88875 & 6,95664 \\
\hline ABR/2001 & 1,66649 & 1,48886 & 0,38560 & 0,73313 & 3,34195 & 4,62655 \\
\hline MAI/2001 & 1,34412 & 0,90022 & 0,25743 & 0,70395 & 2,40389 & 3,21716 \\
\hline JUN/2001 & 1,59480 & 1,36667 & 0,17793 & 0,74822 & - & 3,60115 \\
\hline JUL/2001 & 1,45440 & 0,90392 & 0,11353 & 0,51002 & 2,33858 & 3,45646 \\
\hline AGO/2001 & 1,12501 & 0,81524 & 0,09799 & 0,41457 & 2,02763 & 3,07435 \\
\hline SET/2001 & 1,04101 & 0,60978 & 0,08546 & 0,34740 & 1,55175 & 2,50390 \\
\hline OUT/2001 & 0,90082 & 0,51586 & 0,08632 & 0,33901 & 1,77673 & 2,55696 \\
\hline $\mathrm{NOV} / 2001$ & 0,79617 & 0,37974 & 0,14810 & 0,20684 & 1,42359 & 2,09665 \\
\hline DEZ/2001 & 0,80006 & 0,37312 & 0,10703 & 0,28344 & 1,39744 & 2,30853 \\
\hline
\end{tabular}




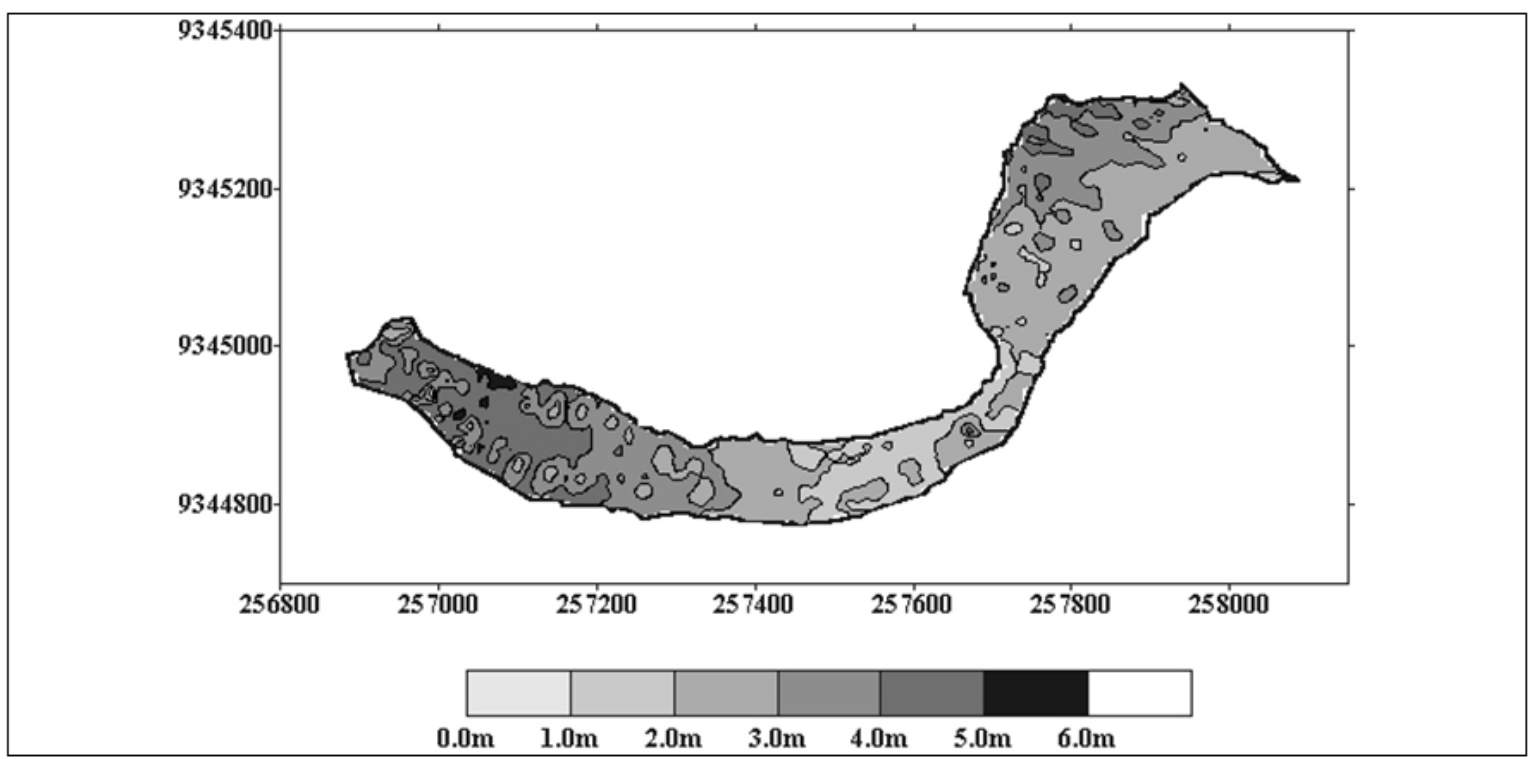

Figura 4 - Mapa da bacia hidráulica e das curvas iso-batimétricas da Lagoa do Jiqui, segundo Santos \& Lucena (2003).

Figure 4-Hydraulic basin map and isobatimetric curves of Jiqui Lagoon (Santos \& Lucena, 2003).

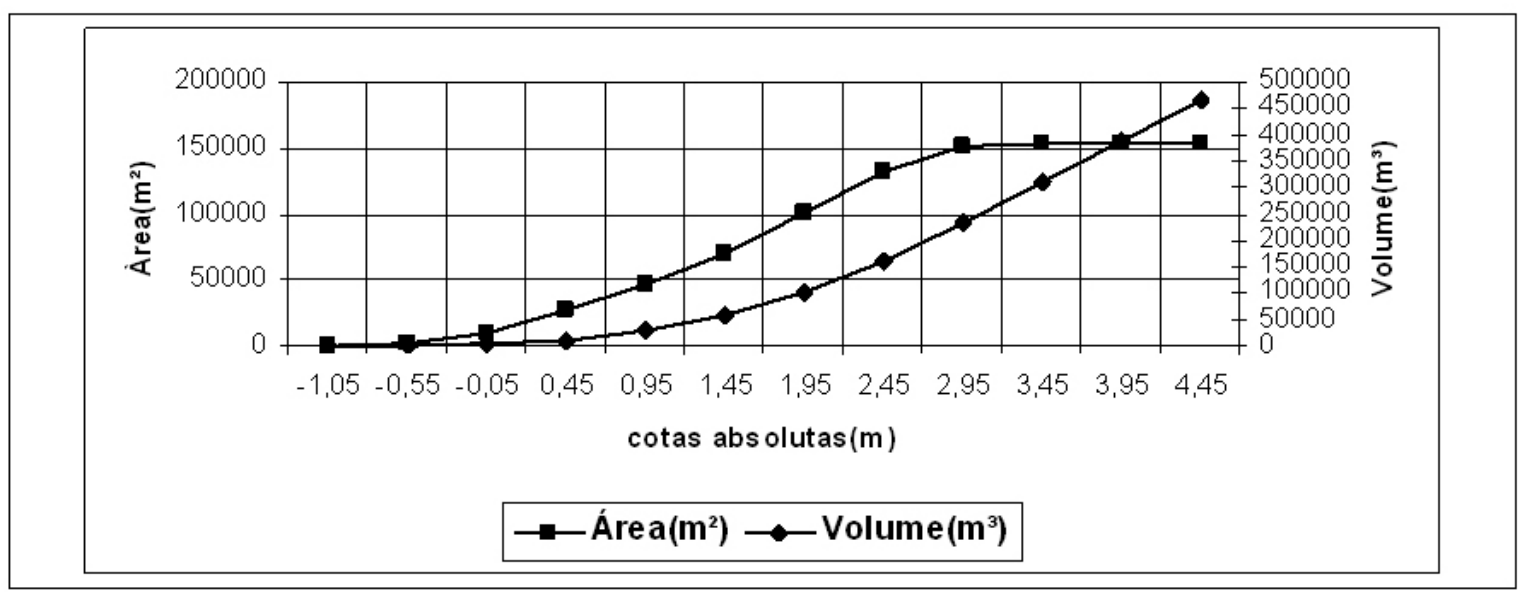

Figura 5 - Curva cota-área-volume da lagoa do Jiqui, segundo Santos \& Lucena (2003).

Figure 5 - Elevation-area-volume curve of Jiqui Lagoon (Santos \& Lucena, 2003).

\section{As Lagoas do Jiqui e Pium}

A Lagoa do Jiqui localiza-se em Parnamirim, próximo ao limite com a zona sul da capital Natal, possuindo um comprimento de 1210 $\mathrm{m}$ e uma largura máxima de $200 \mathrm{~m}$. Encontra-se inserida no próprio leito do Rio Pitimbu, o qual possui uma bacia hidrográfica de $98 \mathrm{~km}^{2}$. Este mesmo rio drena a lagoa, indo desaguar no Riacho Taborda, na localidade Caturana. Sua exploração teve início nos anos 60 através de poços amazonas em suas margens e, posteriormente, com uma tomada d'água na própria lagoa.

Santos \& Lucena (2003), em levantamento batimétrico neste espelho d'água, evidenciaram um volume acumulado de $466.093 \mathrm{~m}^{3}$, numa área de 15,25 ha, uma profundidade máxima de $5,5 \mathrm{~m}$, além do fato de que o fundo da lagoa situa-se a $4,45 \mathrm{~m}$ acima do nível médio do mar. As figuras 4 e 5 exibem a síntese do levantamento batimético e a curva "cota x área x volume" da Lagoa do Jiqui.

A Lagoa do Pium localiza-se nas proximidades da localidade de Pium de Cima, município de Nísia Floresta, distando cerca de $6 \mathrm{~km}$ a sul da Lagoa do Jiqui. Acha-se inserida no leito do Riacho Pium, o qual possui uma bacia hidrográfica de $34 \mathrm{~km}^{2}$, sendo drenada pelo mesmo canal fluvial até o Rio Pirangi em Pium. 


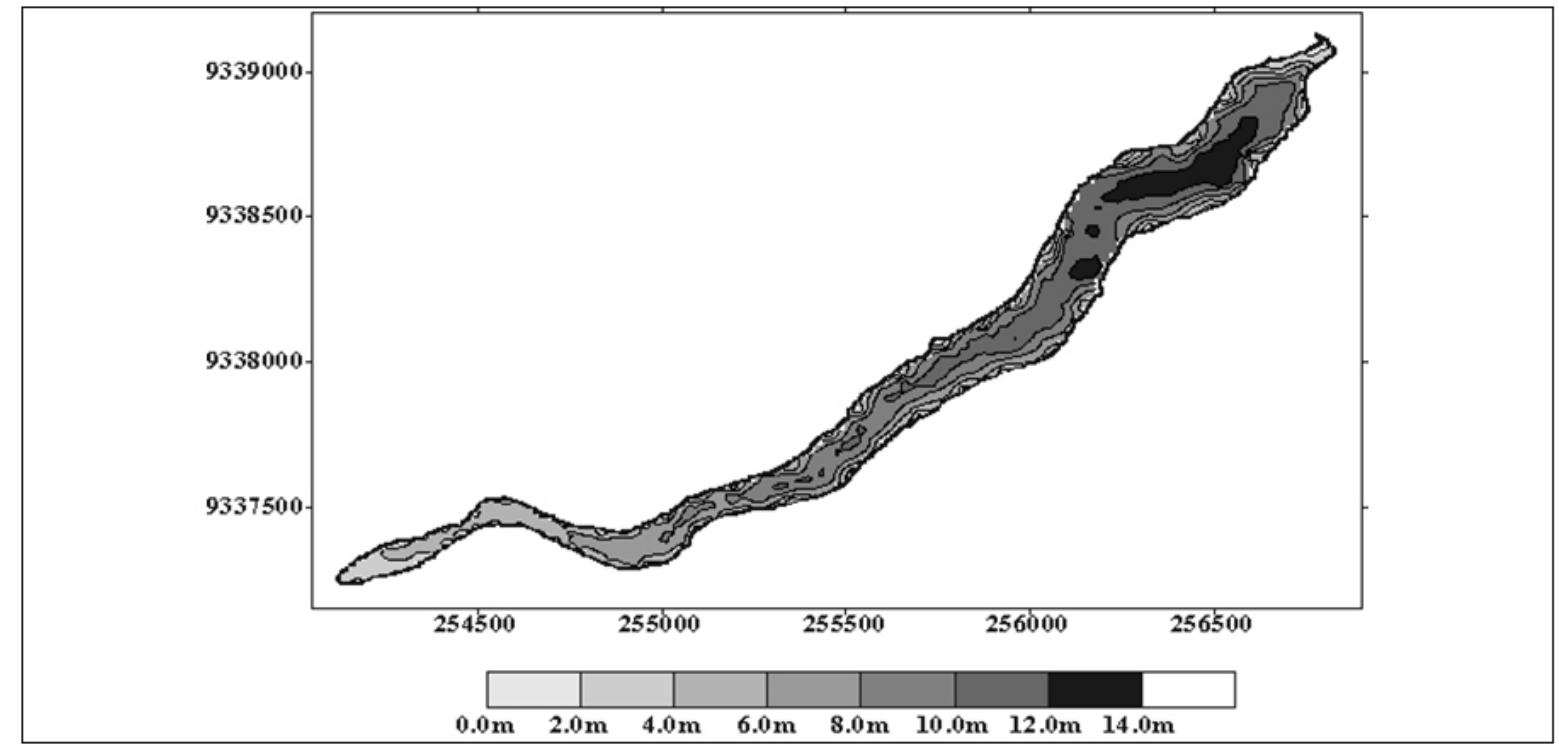

Figura 6 - Mapa da bacia hidráulica e das curvas iso-batimétricas da Lagoa do Pium, segundo Santos \& Lucena (2003).

Figure 6 - Hydraulic basin map and isobatimetric curves of Pium Lagoon (Santos \& Lucena, 2003).

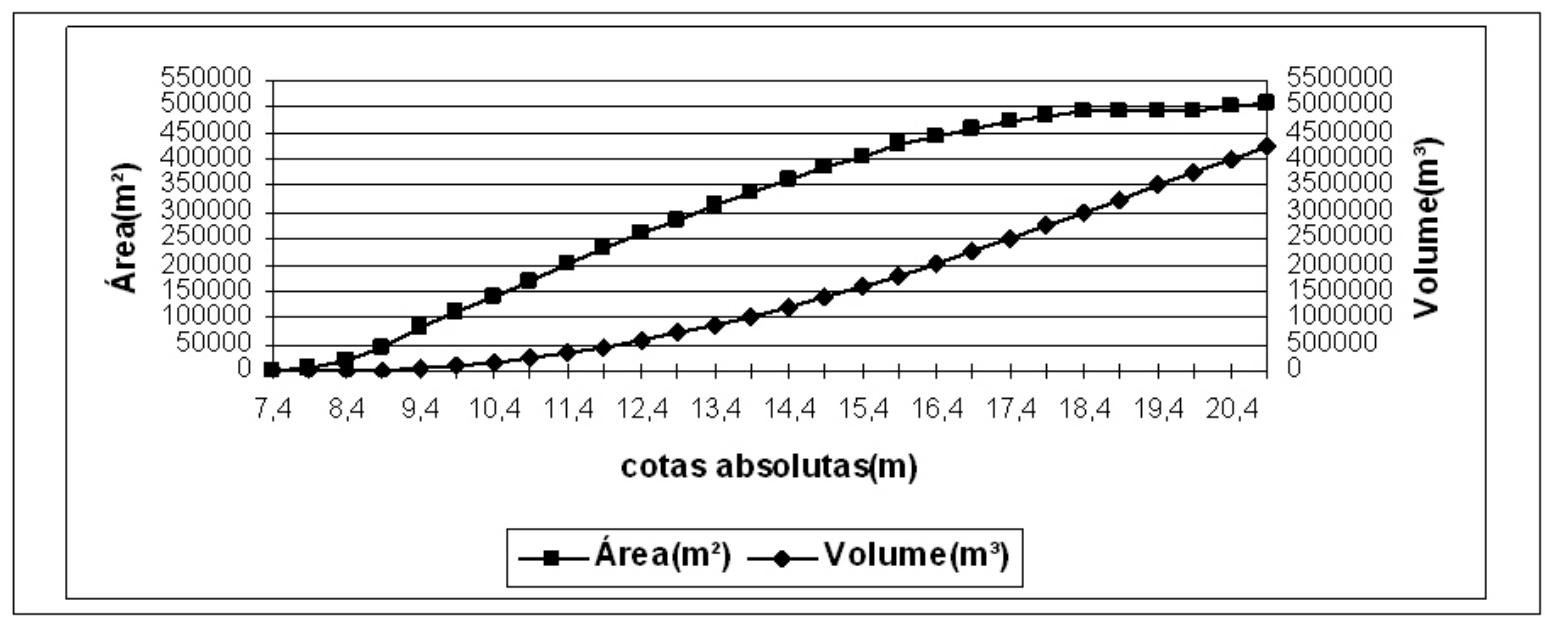

Figura 7 - Curva cota-área-volume da Lagoa do Pium, segundo Santos \& Lucena (2003).

Figure 7 - Elevation-area-volume curve of Pium Lagoon (Santos \& Lucena, 2003).

Alagoa apresenta uma forma estreita e alongada, na direção NE, com $2715 \mathrm{~m}$ de comprimento e largura máxima de $250 \mathrm{~m}$ e, a exemplo da Lagoa do Jiqui, exibe uma considerável interconexão hidráulica com o Aqüífero Barreiras.

Os resultados obtidos por Santos \& Lucena (2003) na referida lagoa dão conta de um volume acumulado de $4.266 .550 \mathrm{~m}^{3}$ em uma área de 49,44 ha, uma profundidade máxima de 13,5 m e o fundo da lagoa situando-se a $20,91 \mathrm{~m}$ acima do nível médio do mar. Observou-se ainda uma profundidade em torno de 9,5 $\mathrm{m}$ em praticamente toda sua extensão. As figuras 6 e 7 exibem a síntese do levantamento batimétrico e a curva "cota x área x volume" da Lagoa do Pium.

\section{A INTERAÇÃO ÁGUAS SUBTERRÂNEAS X ÁGUAS SUPERFICIAIS}

Em termos gerais, o contex to hídrico superficial, incluindo as lagoas do Jiqui e Pium, rios e riachos da área, apresenta relação de efluência com o Aqüífero Barreiras. A exceção deve ser creditada tão somente a um curto período de tempo, invariavelmente logo após a consolidação do período chuvoso no litoral leste do Rio Grande do Norte (Maio-Junho). Esta observação decorre do intervalo de tempo entre o aumento do volume d'água dos rios e riachos, proporcionado pela precipitação direta sobre estas drenagens, e a resposta posterior do aqüífero às chuvas (elevação da superfície potenciométrica).

Lucena (2005), tomando como referência o período de Janeiro de 2000 a Janeiro de 2001 (considerando este um ano de distribuição pluviométrica próxima da normal para a região), além de dados imediatamente anteriores a este intervalo com precipitações nulas ou inferiores 
a $10 \mathrm{~mm}$, considera as descargas observadas em Fevereiro e Março de 2000 como representativas do período de recessão do rio (Lucena et al., 2004). Dessa forma, pode-se dizer que o escoamento do Rio Pirangi durante este período é associado ao fluxo de base proveniente do Aqüífero Barreiras. Os referidos autores, projetando a descarga medida no mês de Março/2000 $\left(1,14 \mathrm{~m}^{3} / \mathrm{s}\right)$ e adotando um coeficiente de recessão de 0,05 dia $^{-1}$ na equação de recessão de um rio $\left(\mathrm{Q}_{\mathrm{t}}=\mathrm{Q}_{0}\right.$ exp- $\alpha \mathrm{t}$, in Feitosa e Manoel Filho, 1997), obtiveram para a descarga relativa ao fluxo de base, decorridos 30 dias após a cessão do evento de recarga, vazões da ordem de $0,25 \mathrm{~m}^{3} / \mathrm{s}$.

As lagoas Jiqui e Pium acham-se igualmente conectadas hidraulicamente com o sistema aqüífero, conforme reportado. A Lagoa do Jiqui situa-se no início da grande zona de descarga subterrânea regional (Figura 2), atuando assim como exutório natural do Aqüífero Barreiras no setor norte-nordeste da bacia do Rio Pirangi. Já a Lagoa do Pium, mostra-se como um reservatório bastante singular, sobretudo em relação às suas descargas medidas de entrada (in) e saída (out). Estas vazões de saída da Lagoa do Pium são sistematicamente maiores de que as vazões de entrada, sem que seu volume acumulado sofra variações consideráveis, de acordo com observações linimétricas diárias efetuadas ao longo dos biênios 2000-2001 (Lucena et al., 2004) e 2007-2008. A aproximada regularização da descarga na lagoa deve ser creditada à contribuição subterrânea do sistema Bonfim, de acordo com a potenciometria da área (Figura 2), podendo ser estimada quantitativamente através da expressão (Feitosa e Manoel Filho, 1997):
$\mathrm{Q}=\mathrm{T}$ i 1

Adotando-se uma transmissividade local de $5,5 \mathrm{~m}^{2} / \mathrm{h}$ (modificado de Costa, 1997), um gradiente hidráulico de 0,0108 (avaliado no mapa da Figura 2) e uma frente de escoamento de 3780 metros (frente de escoamento X-Y na Figura 2), a descarga subterrânea que aporta na margem direita da Lagoa do Pium, proveniente do sistema Bonfim, é de aproximadamente $224 \mathrm{~m}^{3} / \mathrm{h}$ (Lucena et al., 2004). Segundo estes mesmos procedimentos e adotando-se uma transmissividade de 186,6 $\mathrm{m}^{2} / \mathrm{h}$, proveniente de teste de aqǘf́ero efetuado na margem esquerda da Lagoa do Jiqui (Lucena, 2005), uma frente de escoamento de 1500 metros e gradiente hidráulico de 0,0034 , a descarga que aporta na margem esquerda da referida lagoa é de aproximadamente $960 \mathrm{~m}^{3} / \mathrm{h}$.

\section{A DISPONIBILIDADE HÍDRICA DAS LAGOAS JIQUI E PIUM}

Dentre as poucas estações fluviométricas existentes no litoral leste do Rio Grande do Norte, tomou-se como referência, com vistas à modelagem hidrológica nas sub-bacias Jiqui e Pium, a estação Dom Marcolino no Rio Maxaranguape ( $-5^{\circ} 48^{\prime}$ 6 "'S e $\left.-35^{\circ} 23^{\prime} 15^{\prime \prime} \mathrm{W}\right)$. Esta estação foi escolhida devido a sua similaridade geográfica, climática, ambiental e geológica com a bacia do Rio Pirangi. Os valores médios mensais de vazão observadas nesta estação são mostrados na Tabela 3.

No tocante aos dados pluviométricos, 05 postos (operados pela Empresa de Pesquisa Agropecuária do rio Grande do Norte - EMPARN) foram considerados no presente estudo por apresentarem séries mais longas e reduzidas falhas (Tabela 4).

Tabela 3 - Vazões observadas na estação Dom Marcolino.

Table 3 - Discharges observed on Dom Marcolino gauging station.

\begin{tabular}{|l|c|c|c|c|c|c|c|c|c|c|c|c|}
\hline ANO & JAN & FEV & MAR & ABR & MAI & JUN & JUL & AGO & SET & OUT & NOV & DEZ \\
\hline $\mathbf{2 0 0 0}$ & 1.630 & 1.764 & - & 3.160 & 2.931 & 4.732 & 6.233 & 3.591 & 2.582 & 2.191 & 2.029 & 2.066 \\
\hline $\mathbf{2 0 0 1}$ & 1.928 & 1.764 & 1.980 & 2.913 & 1.950 & 2.885 & 2.566 & 2.196 & 2.028 & 1.730 & 1.664 & 1.680 \\
\hline $\mathbf{2 0 0 2}$ & 2.321 & 1.852 & 2.956 & 2.672 & 2.204 & 3.333 & 2.560 & 2.986 & 2.161 & 2.231 & 2.080 & 2.283 \\
\hline $\mathbf{2 0 0 3}$ & 2.122 & 2.573 & 4.099 & 2.972 & 2.412 & 2.936 & 2.616 & 2.207 & 2.074 & 1.759 & 1.649 & 1.627 \\
\hline $\mathbf{2 0 0 4}$ & 4.897 & 3.612 & 3.003 & 3.250 & 3.421 & 13.500 & 12.551 & 1.766 & 2.445 & 1.894 & 1.817 & 1.866 \\
\hline $\mathbf{2 0 0 5}$ & 1.814 & 1.743 & 3.157 & 2.151 & 5.483 & 11.901 & 6.702 & 2.523 & 2.799 & 2.043 & 1.952 & 1.665 \\
\hline $\mathbf{2 0 0 6}$ & 1.632 & 1.543 & 2.002 & 3.174 & 2.327 & 3.542 & 2.389 & - & 1.719 & 1.412 & 1.500 & 1.328 \\
\hline
\end{tabular}


Tabela 4 - Relação de postos pluviométricos de interesse para a bacia do Rio Pirangi.

Table 4 - Relationship of rain-gauge station of interest for Pirangi River basin.

\begin{tabular}{|c|c|c|c|c|c|}
\hline $\mathbf{N}^{\circ}$ & NOME & CÓDIGO & LATITUDE & LONGITUDE & $\begin{array}{c}\text { ANO } \\
\text { INST. }\end{array}$ \\
\hline $\mathbf{1}$ & UFRN & 3819657 & $5^{\circ} 48^{\prime}$ & $35^{\circ} 13^{\prime}$ & 1910 \\
\hline $\mathbf{2}$ & Piripiri & 3819731 & $5^{\circ} 54^{\prime}$ & $35^{\circ} 22^{\prime}$ & 1911 \\
\hline $\mathbf{3}$ & Parnamirim & 3819844 & $5^{\circ} 54^{\prime}$ & $35^{\circ} 16^{\prime}$ & 1992 \\
\hline $\mathbf{4}$ & Monte Alegre & 3829135 & $6^{\circ} 04^{\prime}$ & $35^{\circ} 20^{\prime}$ & 1992 \\
\hline $\mathbf{5}$ & Nísia Floresta & 3829182 & $6^{\circ} 05^{\prime}$ & $35^{\circ} 12^{\prime}$ & 1992 \\
\hline
\end{tabular}

Tabela 5 - Precipitação anual no período de 1992 a 2005 (sub-bacias Jiqui e Pium).

Table 5 - Annual precipitation on 1992-2005 period (Jiqui and Pium sub-basins).

\begin{tabular}{|c|c|c|c|}
\hline ANO & PIRANGI & JIQUI & PIUM \\
\hline $\mathbf{1 9 9 2}$ & $1.228,6$ & $1.247,3$ & \\
\hline $\mathbf{1 9 9 3}$ & 714,1 & 712,2 & 771,1 \\
\hline $\mathbf{1 9 9 4}$ & $2.049,5$ & $2.134,1$ & $2.060,1$ \\
\hline $\mathbf{1 9 9 5}$ & $1.401,9$ & $1.485,9$ & $1.345,5$ \\
\hline $\mathbf{1 9 9 6}$ & $1.164,8$ & $1.223,7$ & $1.161,3$ \\
\hline $\mathbf{1 9 9 7}$ & $1.153,1$ & $1.181,4$ & $1.160,3$ \\
\hline $\mathbf{1 9 9 8}$ & $1.196,1$ & $1.347,6$ & $1.086,6$ \\
\hline $\mathbf{1 9 9 9}$ & 830,3 & 900,7 & 773,5 \\
\hline $\mathbf{2 0 0 0}$ & $1.895,9$ & $2.003,3$ & $1.820,9$ \\
\hline $\mathbf{2 0 0 1}$ & 880,4 & 950,1 & 854,5 \\
\hline $\mathbf{2 0 0 2}$ & $1.580,3$ & $1.670,2$ & $1.556,8$ \\
\hline $\mathbf{2 0 0 3}$ & $1.259,2$ & $1.302,2$ & $1.293,0$ \\
\hline $\mathbf{2 0 0 4}$ & $1.897,8$ & $2.036,0$ & $1.792,8$ \\
\hline $\mathbf{2 0 0 5}$ & $1.512,5$ & $1.632,5$ & $1.458,0$ \\
\hline $\mathbf{M E ́ D I A}$ & $\mathbf{1 . 3 4 0 , 3}$ & $\mathbf{1 . 4 1 6 , 2}$ & $\mathbf{1 . 3 1 8 . 0}$ \\
\hline
\end{tabular}

Os dados pluviométricos disponíveis permitiram a obtenção de uma série diária de precipitação médiana bacia Pirangi enas sub-bacias Pium e Jiqui, no período de 1992 a 2005 (tabela 5). Os dados de evapotranspiração considerados foram aqueles da estação climatológica de Natal, instalada na UFRN (tabela 6).

\section{ASPECTOS METODOLÓGICOS E CALIBRAÇÃO DO MODELO HIDROLÓGICO}

$\mathrm{Na}$ avaliação dos processos hidrológicos terrestres de transformação da chuva em vazão na bacia do Rio Pirangi, foi necessário inicialmente ajustar um modelo chuva-vazão para os pontos pluviométricos e fluviométricos selecionados e utilizar os parâmetros ajustados para gerar as vazões em cada um dos pontos de interesse na
Tabela 6 - Evapotranspiração potencial média na estação climatológica de Natal.

Table 6 - Evapotranspiration potential average on Natal-RN State climatological station.

\begin{tabular}{|c|c|c|c|}
\hline \multirow{2}{*}{ Mês } & EVP & ETP & Média Daria \\
\cline { 2 - 4 } & $\mathbf{( m m )}$ & $\mathbf{( m m})$ & $\mathbf{( m m / d i a )}$ \\
\hline Jan & 212.5 & 148.7 & 4.8 \\
\hline Fev & 212.8 & 134.5 & 4.8 \\
\hline Mar & 178.1 & 120.7 & 4.0 \\
\hline Abr & 146.3 & 102.4 & 3.3 \\
\hline Mai & 140.9 & 95.5 & 3.2 \\
\hline Jun & 111.6 & 75.6 & 2.5 \\
\hline Jul & 129.9 & 90.9 & 2.9 \\
\hline Ago & 169.7 & 118.8 & 3.8 \\
\hline Set & 204.9 & 138.8 & 4.6 \\
\hline Out & 226.3 & 158.4 & 5.1 \\
\hline Nov & 233.9 & 158.5 & 5.3 \\
\hline Dez & 216.2 & 151.3 & 4.9 \\
\hline Ano & $\mathbf{2 . 1 8 3 , 0}$ & $\mathbf{1 . 4 9 4 , 0}$ & \\
\hline
\end{tabular}

bacia. Nessa transformação chuva-vazão, utilizouse o modelo matemático hidrológico MODHAC (Lanna e Schwarzbach, 1989; Lanna, 1997), o qual tem sido amplamente utilizado no Nordeste com excelentes resultados. Este modelo simula a fase terrestre do ciclo hidrológico (transformação chuva-vazão), com calibração automática de seus parâmetros, possibilitando o aprimoramento do índice de aderência entre as vazões observadas e aquelas calculadas.

Conforme reportado, a calibração do modelo foi realizada na estação fluviométrica de Dom Marcolino, na bacia do Rio Maxaranguape, face as suas similaridades com a bacia do Rio Pirangi e ausência de estações nesta última. A Tabela 7 apresenta o conjunto de parâmetros obtido na referida calibração. 
Tabela 7 - Parâmetros calibrados do MODHAC para a estação Dom Marcolino.

Table 7 -Calibrated parameters of the MODHAC model for Dom Marcolino gauging station.

\begin{tabular}{|c|c|c|c|c|c|c|c|c|c|c|c|}
\hline RSPX & RSSX & RSBX & RSBF & IMAX & IMIN & IDEC & ASP & ASS & ASB & PRED & CEVA \\
\hline 38,98 & 266,7 & 129,4 & 9,428 & 90,0 & 40,36 & 1 & 0,9 & 0,0005 & $3,38 \times 10^{-3}$ & 999 & $3,09 \times 10^{-3}$ \\
\hline
\end{tabular}

\section{SIMULAÇÃO DAS LAGOAS JIQUI E PIUM}

Considerando o conjunto de parâmetros apresentados na Tabela 7, gerou-se uma série de vazões médias mensais afluentes à Lagoa do Jiqui e Pium para o período de 1992 a 2005 (Lagoa do Jiqui) e 1994 a 2005 (Lagoa do Pium). As vazões médias mensais são mostradas nas tabelas 8 e 9 , respectivamente.

Na presente determinação da disponibilidade hídrica das lagoas, considerou-se que as mesmas comportam-se como açudes, ou seja, não considerando a contribuição subterrânea afluente. Neste sentido, esta avaliação foi realizada utilizando-se a equação do balanço hídrico, a qual contabiliza todas as afluências e todas as retiradas ou eventuais sangrias. A equação do balanço hídrico é dada por:

\section{Onde:}

$$
S(t+1)=S(t)+Q(t)-D(t)-E(t)-V(t)
$$

$\mathrm{S}(\mathrm{t}+1)$ é o armazenamento na lagoa no final do mês t;

$\mathrm{S}(\mathrm{t})$ é o armazenamento na lagoa no início do mês t;

$\mathrm{Q}(\mathrm{t})$ é o volume afluente a lagoa no mês t;

$\mathrm{D}(\mathrm{t})$ é a defluência da lagoa para atendimento à demanda a ser suprida no mês t;

$E(t)$ é o volume de perdas por evaporação descontada da chuva sobre a superfície da lagoa no mês t;

$V(t)$ é a sangria da lagoa (defluência) durante o mês t.

O limite considerado é $\mathrm{Smin} \leq \mathrm{S}(\mathrm{t}+1) \leq \mathrm{Smax}$, sendo $\mathrm{S}_{\max }$ o limite máximo do armazenamento da lagoa e $\mathrm{S}_{\min }$ o limite mínimo de armazenamento da lagoa considerado aceitável. A evaporação é computada considerando-se a área média da superfície da lagoa no mês em pauta, ou seja:

Onde:

$$
E(t)=[e(t)-p(t)]^{*}\{[A(t)+A(t+1)] / 2\}
$$

e(t) é a taxa mensal de evaporação aplicável ao local ( $\mathrm{mm} / \mathrm{mês})$;

$\mathrm{p}(\mathrm{t})$ é a precipitação sobre a superfície líquida da lagoa ( $\mathrm{mm} / \mathrm{mês})$;

$\mathrm{A}(\mathrm{t})$ e $\mathrm{A}(\mathrm{t}+1)$ são as áreas da superfície da lagoa, $\left(\mathrm{Km}^{2}\right)$.
Os dados hidro-climatológicos utilizados nas simulações das lagoas do Jiqui e do Pium foram as vazões médias mensais afluentes as lagoas (provenientes da modelagem das bacias de contribuição utilizando o modelo MODAHC e o conjunto de dados calibrados para a estação Dom Marcolino), precipitações médias mensais nas áreas das lagoas, evaporações médias mensais na área de espelho d'água das lagoas (tomando-se como referência os dados da estação climatológica da UFRN-Natal) e relação "Cota de inundação Área inundada - Volume acumulado" das lagoas, dados estes já reportados.

Para estimar a vazão regularizada na Lagoa do Jiqui, foram simulados dois cenários de condições iniciais: (i) lagoa cheia no início do período de simulação e (ii) lagoa com somente $50 \%$ de sua capacidade no início do período; e três cenários de volume mínimo da lagoa: (i) volume mínimo de $0,1 \mathrm{Hm}^{3}$, correspondente a cota $1,95 \mathrm{~m}$; (ii) volume mínimo de $0,2 \mathrm{Hm}^{3}$, correspondente a cota $2,95 \mathrm{~m}$ e (iii) volume mínimo de $0,3 \mathrm{Hm}^{3}$, correspondente a cota $3,45 \mathrm{~m}$.

As vazões regularizadas da Lagoa do Jiqui para diferentes níveis de garantia e nos cenários analisados são mostradas na Tabela 10 e Figura 8 , respectivamente. Observa-se que as condições iniciais da lagoa não influenciam o valor da vazão regularizada para os menores níveis de garantia, tendo uma pequena influência somente para $100 \%$ de garantia, indicando que o tamanho da série de vazões afluentes utilizada representou satisfatoriamente a variabilidade temporal deste parâmetro na bacia.

No cálculo da vazão regularizada da Lagoa do Pium, para diferentes níveis de garantia, foram considerados dois cenários de condições iniciais da lagoa: (i) lagoa cheia no início do período de simulação e (ii) lagoa com somente $50 \%$ de sua capacidade no início do período; e três cenários de volume mínimo da lagoa: (i) volume mínimo de 1 $\mathrm{Hm}^{3}$, correspondente a cota $13,91 \mathrm{~m}$; (ii) volume mínimo de $2 \mathrm{Hm}^{3}$, correspondente a cota $16,41 \mathrm{~m}$ e (iii) volume mínimo de $3 \mathrm{Hm}^{3}$, correspondente a cota $18,42 \mathrm{~m}$. 
Tabela 8 - Série de vazões médias mensais $\left(\mathrm{m}^{3} / \mathrm{s}\right)$ afluentes a Lagoa do Jiqui, no período de 1992 a 2005.

Table 8 - Mean monthly discharge series flow in to Jiqui Lagoon, period of 1992-2005.

\begin{tabular}{|l|c|c|c|c|c|c|c|c|c|c|c|c|}
\hline \multirow{2}{*}{ Ano } & \multicolumn{10}{|c|}{ Meses } \\
\cline { 2 - 12 } & Jan & Fev & Mar & Abr & Mai & Jun & Jul & Ago & Set & Out & Nov & Dez \\
\hline $\mathbf{1 9 9 2}$ & 0,022 & 0,449 & 0,808 & 2,636 & 0,909 & 0,942 & 0,906 & 0,870 & 0,814 & 0,715 & 0,663 & 0,638 \\
\hline $\mathbf{1 9 9 3}$ & 0,604 & 0,613 & 0,607 & 0,798 & 0,812 & 0,805 & 0,832 & 0,803 & 0,734 & 0,736 & 0,734 & 0,699 \\
\hline $\mathbf{1 9 9 4}$ & 0,789 & 0,856 & 0,813 & 0,982 & 4,390 & 25,000 & 13,505 & 0,903 & 0,864 & 0,778 & 0,707 & 0,673 \\
\hline $\mathbf{1 9 9 5}$ & 0,692 & 0,738 & 2,191 & 0,916 & 10,617 & 0,952 & 9,883 & 0,892 & 0,821 & 0,718 & 0,697 & 0,642 \\
\hline $\mathbf{1 9 9 6}$ & 0,684 & 0,711 & 0,817 & 1,302 & 3,060 & 0,928 & 0,868 & 0,869 & 0,830 & 0,773 & 0,781 & 0,749 \\
\hline $\mathbf{1 9 9 7}$ & 0,674 & 0,774 & 0,831 & 6,050 & 4,915 & 0,915 & 0,864 & 0,844 & 0,753 & 0,669 & 0,595 & 0,599 \\
\hline $\mathbf{1 9 9 8}$ & 0,735 & 0,816 & 0,767 & 0,815 & 0,815 & 0,863 & 16,793 & 0,945 & 0,852 & 0,762 & 0,678 & 0,628 \\
\hline $\mathbf{1 9 9 9}$ & 0,612 & 0,680 & 0,811 & 0,798 & 2,085 & 0,888 & 0,829 & 0,782 & 0,776 & 0,738 & 0,680 & 0,736 \\
\hline $\mathbf{2 0 0 0}$ & 0,796 & 0,786 & 0,801 & 0,876 & 2,480 & 12,386 & 13,585 & 4,319 & 2,097 & 0,855 & 0,748 & 0,707 \\
\hline $\mathbf{2 0 0 1}$ & 0,741 & 0,753 & 0,745 & 0,853 & 0,850 & 2,135 & 0,904 & 0,861 & 0,793 & 0,698 & 0,623 & 0,671 \\
\hline $\mathbf{2 0 0 2}$ & 0,764 & 0,877 & 3,154 & 2,464 & 1,512 & 4,723 & 0,942 & 4,211 & 0,837 & 0,766 & 0,706 & 0,720 \\
\hline $\mathbf{2 0 0 3}$ & 0,679 & 0,821 & 0,878 & 0,934 & 2,919 & 2,072 & 0,939 & 0,880 & 0,827 & 0,741 & 0,706 & 0,693 \\
\hline $\mathbf{2 0 0 4}$ & 4,743 & 8,886 & 0,949 & 0,903 & 1,304 & 15,594 & 11,198 & 0,888 & 0,799 & 0,750 & 0,700 & 0,637 \\
\hline $\mathbf{2 0 0 5}$ & 0,570 & 0,579 & 0,646 & 0,808 & 6,897 & 29,141 & 1,799 & 0,887 & 0,832 & 0,761 & 0,699 & 0,632 \\
\hline
\end{tabular}

Tabela 9 - Série de vazões médias mensais $\left(\mathrm{m}^{3} / \mathrm{s}\right)$ geradas na bacia Pium -1994 a 2005.

Table 9 - Mean monthly discharge series flow in to Pium Lagoon, period of 1994 -2005.

\begin{tabular}{|c|c|c|c|c|c|c|c|c|c|c|c|c|}
\hline \multirow{2}{*}{ Ano } & \multicolumn{10}{|c|}{ Meses } & \multicolumn{10}{|c|}{ Ong } \\
\cline { 2 - 13 } & Jan & Fev & Mar & Abr & Mai & Jun & Jul & Ago & Set & Out & Nov & Dez \\
\hline $\mathbf{1 9 9 4}$ & 0,2561 & 0,2701 & 0,2692 & 0,3839 & 1,3034 & 6,6924 & 4,0886 & 0,2877 & 0,2743 & 0,2442 & 0,2200 & 0,2105 \\
\hline $\mathbf{1 9 9 5}$ & 0,2249 & 0,2332 & 0,4255 & 0,2859 & 1,6484 & 0,3011 & 2,8810 & 0,2817 & 0,2562 & 0,2246 & 0,2268 & 0,2110 \\
\hline $\mathbf{1 9 9 6}$ & 0,2179 & 0,2294 & 0,2528 & 0,2773 & 0,5792 & 0,2969 & 0,2795 & 0,2817 & 0,2661 & 0,2462 & 0,2463 & 0,2366 \\
\hline $\mathbf{1 9 9 7}$ & 0,2163 & 0,2395 & 0,2592 & 1,5214 & 0,6591 & 0,2905 & 0,2768 & 0,2670 & 0,2407 & 0,2162 & 0,1946 & 0,2486 \\
\hline $\mathbf{1 9 9 8}$ & 0,2480 & 0,2617 & 0,2415 & 0,2572 & 0,2563 & 0,2666 & 2,1712 & 0,2984 & 0,2667 & 0,2383 & 0,2142 & 0,2024 \\
\hline $\mathbf{1 9 9 9}$ & 0,2007 & 0,2159 & 0,2478 & 0,2497 & 0,8130 & 0,2765 & 0,2594 & 0,2436 & 0,2374 & 0,2252 & 0,2077 & 0,2221 \\
\hline $\mathbf{2 0 0 0}$ & 0,2533 & 0,2637 & 0,2544 & 0,2740 & 0,2907 & 3,4225 & 3,5906 & 0,6963 & 0,3090 & 0,2721 & 0,2381 & 0,2276 \\
\hline $\mathbf{2 0 0 1}$ & 0,2368 & 0,2312 & 0,2363 & 0,2634 & 0,2635 & 0,4752 & 0,2771 & 0,2651 & 0,2455 & 0,2200 & 0,2075 & 0,2305 \\
\hline $\mathbf{2 0 0 2}$ & 0,2482 & 0,2715 & 1,1546 & 0,3023 & 0,2898 & 0,5848 & 0,2966 & 1,5686 & 0,2674 & 0,2547 & 0,2401 & 0,2368 \\
\hline $\mathbf{2 0 0 3}$ & 0,2245 & 0,2665 & 0,3945 & 0,2983 & 0,2935 & 0,6106 & 0,2992 & 0,2835 & 0,2614 & 0,2359 & 0,2217 & 0,2166 \\
\hline $\mathbf{2 0 0 4}$ & 0,2517 & 1,9370 & 0,3003 & 0,2882 & 0,2937 & 3,2916 & 2,7396 & 0,2869 & 0,2634 & 0,2439 & 0,2295 & 0,2110 \\
\hline $\mathbf{2 0 0 5}$ & 0,1986 & 0,2121 & 0,2327 & 0,2596 & 1,2461 & 6,8092 & 0,4071 & 0,2819 & 0,2659 & 0,2431 & 0,2210 & 0,2007 \\
\hline
\end{tabular}

Tabela 10 - Vazões regularizadas pela Lagoa do Jiqui para diferentes níveis de garantia (valores em $\mathrm{m}^{3} / \mathrm{s}$ ).

Table 10 - Jiqui Lagoon regularized discharge for different warranty levels $\left(\mathrm{m}^{3} / \mathrm{s}\right)$.

\begin{tabular}{|c|c|c|c|}
\hline GARANTIA & $\mathbf{1 0 0} \%$ & $\mathbf{9 5 \%}$ & $\mathbf{9 0 \%}$ \\
\hline \multicolumn{5}{|c|}{ VOLUME INICIAL $=\mathbf{1 0 0} \%$} & 0,711 \\
\hline Vmin $=0,1 \mathrm{Hm}^{3}$ & 0,637 & 0,687 & 0,694 \\
\hline Vmin $=0,2 \mathrm{Hm}^{3}$ & 0,628 & 0,673 & 0,680 \\
\hline$V \min =0,3 \mathrm{Hm}^{3}$ & 0,619 & 0,657 & 0,711 \\
\hline \multicolumn{5}{|c|}{ VOLUME INICIAL $=\mathbf{5 0 \%}$} & 0,694 \\
\hline Vmin $=0,1 \mathrm{Hm}^{3}$ & 0,618 & 0,687 & 0,680 \\
\hline Vmin $=0,2 \mathrm{Hm}^{3}$ & 0,599 & 0,674 & 0,657 \\
\hline
\end{tabular}




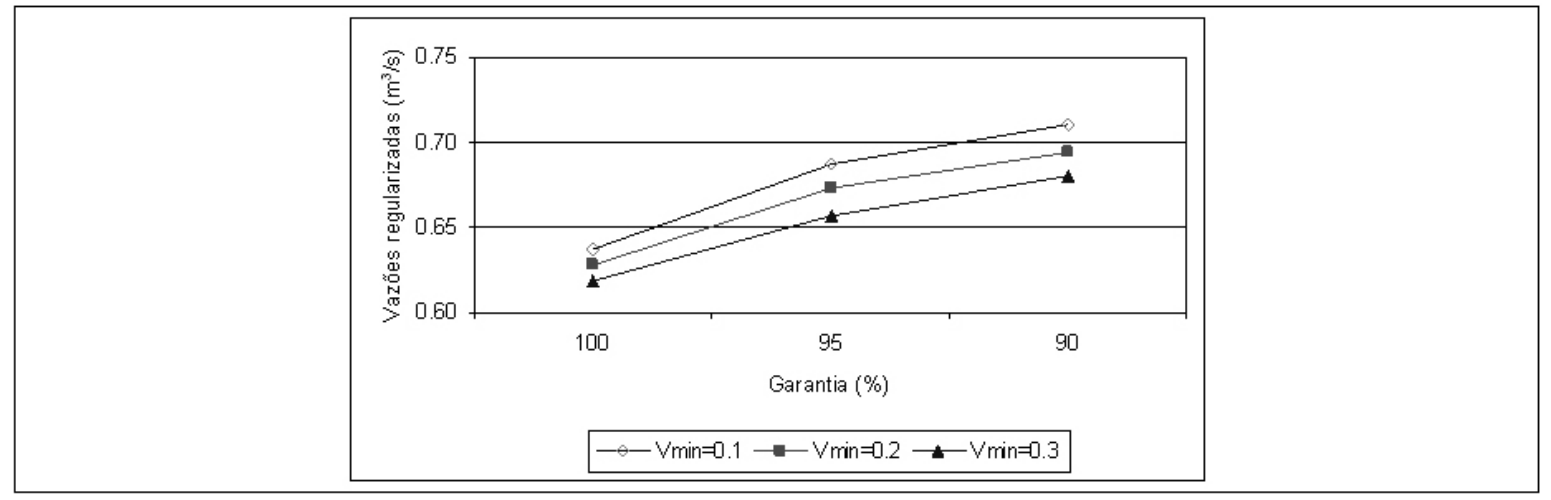

Figura 8 - Curva de garantia da Lagoa do Jiqui.

Figure 8 - Jiqui Lagoon warranty curves.

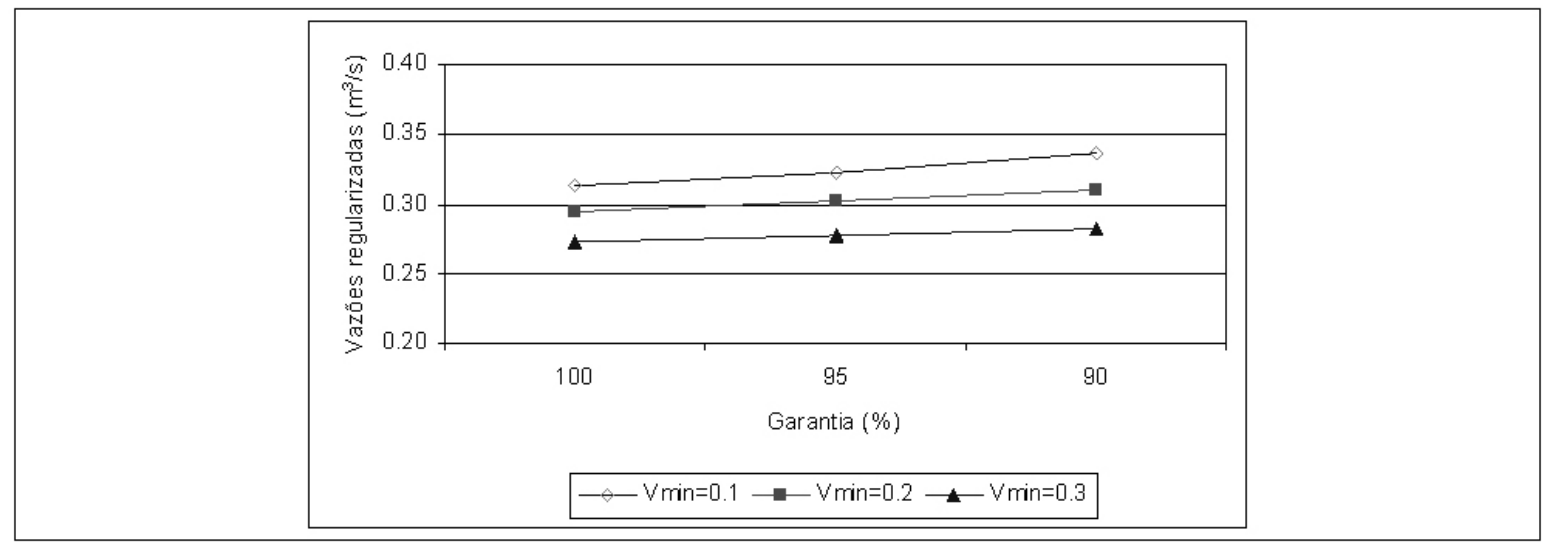

Figura 9 - Curva de garantia da Lagoa do Pium.

Figure 9 - Pium Lagoon warranty curves.

A Tabela 11 apresenta as vazões regularizadas da Lagoa do Pium para diferentes níveis de garantia e nos cenários analisados (Figura 9). Assim como observado na Lagoa do Jiqui, a vazão regularizada pela Lagoa do Pium apresenta variação inferior a $10 \%$ nos diferentes cenários simulados. A vazão regularizada final variou entre 8,6 e $10,6 \mathrm{Hm}^{3}$ /ano, para garantias de $100 \%$ a $90 \%$ e volume mínimo entre 0,1 e $0,3 \mathrm{Hm}^{3}$.

Tabela 11 - Vazões regularizadas pela Lagoa do Pium para diferentes níveis de garantia (valores $\mathrm{em} \mathrm{m}^{3} / \mathrm{s}$ ).

Table 11 - Pium Lagoon regularized discharge for different warranty levels $\left(\mathrm{m}^{3} / \mathrm{s}\right)$.

\begin{tabular}{|c|c|c|c|}
\hline GARANTIA & 100 & 95 & 90 \\
\hline \multicolumn{3}{|c|}{ VOLUME INICIAL $=100 \%$} \\
\hline Vmin = 1 Hm3 & 0,313 & 0,323 & 0,337 \\
\hline Vmin = 2 Hm3 & 0,295 & 0,302 & 0,310 \\
\hline Vmin = 3 Hm3 & 0,273 & 0,277 & 0,282 \\
\hline \multicolumn{4}{|c|}{ VOLUME INICIAL $=50 \%$} \\
\hline $\begin{array}{c}\text { Vmin =0,1 } \\
\text { Hm3 }\end{array}$ & 0,310 & 0,328 & 0,343 \\
\hline $\begin{array}{c}\text { Vmin =0,2 } \\
\text { Hm3 }\end{array}$ & 0,278 & 0,305 & 0,313 \\
\hline $\begin{array}{c}\text { Vmin =0,3 } \\
\text { Hm3 }\end{array}$ & 0,252 & 0,282 & 0,286 \\
\hline
\end{tabular}

\section{SÍNTESE CONCLUSIVA E CONSIDERA- ÇÕES FINAIS}

No contexto hidrogeológico do setor oriental da bacia do Rio Pirangi, a potenciometria do Aqüífero Barreiras evidenciou a existência de uma zona de recarga principal, situada na área da sede municipal de Parnamirim e uma secundária, situada ao norte da Lagoa do Bonfim (no limite sul da bacia), enquanto que a zona de descarga regional é compreendida pela região dos baixos cursos dos rios Pitimbu (incluindo a Lagoa do Jiqui), Pirangi e Riacho Taborda.

No contexto hidrológico superficial, o monitoramento de descargas efetuado no presente estudo revelou valores de 0,12 a 0,74 $\mathrm{m}^{3} / \mathrm{s}$ para o Riacho Pium e 0,67 a $1,69 \mathrm{~m}^{3} / \mathrm{s}$ para o Rio Pitimbu, sendo tais vazões diretamente relacionadas ao regime pluviométrico do litoral leste do Estado. As lagoas do Jiqui e Pium, alvo de levantamentos de seus volumes armazenados, dão conta de valores da ordem de 466.000 e 4.265 .000 $\mathrm{m}^{3}$, respectivamente. A modelagem hidrológica assinalou vazões regularizadas de cerca de 8,6 a $10,6 \mathrm{Hm}^{3} /$ ano, para garantias de $100 \%$ a $90 \%$ e 
volume mínimo entre 0,1 e $0,3 \mathrm{Hm}^{3}$ para a Lagoa do Pium (disponibilidade de até $1000 \mathrm{~m}^{3} / \mathrm{h}$ ), e 19,5 a $22,4 \mathrm{Hm}^{3} /$ ano, para garantias entre $100 \%$ e $90 \%$ e volume mínimo entre 0,1 e $0,3 \mathrm{Hm}^{3}$ para a Lagoa do Jiqui (disponibilidade de $2100 \mathrm{~m}^{3} / \mathrm{h}$ ). Este último valor, somado com a produção de cinco poços tubulares (PT-1, PT-2, PT-3, PT-4 e PT-5), além de outros dois a serem executados (PT-6 e PT-7) pela CAERN projetam uma disponibilidade total do Sistema Jiqui da ordem de $2.800 \mathrm{~m}^{3} / \mathrm{h}$, representando um aumento de $64 \%$ no abastecimento, quando comparado com aquele praticado no início de $2007\left(1.700 \mathrm{~m}^{3} / \mathrm{h}\right.$, em média).

Ressalta-se que, apesar de todo o contexto hidrológico superficial comportar-se como de natureza efluente em relação ao Aqüífero Barreiras, sobretudo as lagoas Jiqui e Pium, as avaliações de disponibilidades e modelagem destas últimas não consideraram tais contribuições subterrâneas. Tal procedimento confere um percentual de garantia adicional aos volumes regularizados das referidas lagoas.

Em termos de recomendações adicionais, dois aspectos devem ser ressaltados. O primeiro diz respeito à necessidade de preservação das margens das principais drenagens da bacia do Rio Pirangi, incluindo as áreas circunvizinhas das lagoas do Jiqui e Pium, bem como a continuidade do monitoramento quantitativo-qualitativo destes mananciais e do Aqüífero Barreiras, tendo em vista que ambos tratam-se de reservas hídricas vitais e estratégicas, principalmente para os grandes centros populacionais de Natal e Parnamirim-RN. O outro se refere à elaboração de estudos hidrogeológicos que contemplem a área situada entre a bacia do Rio Pirangi e a Lagoa do Bonfim, face à conexão hidráulica entre ambos, a fim de aperfeiçoar eventuais balanços hídricos globais dos dois sistemas. Tais estudos devem contemplar um detalhamento do levantamento geológico e geo-elétrico da área, a elaboração de uma potenciometria local, bem como a perfuração de piezômetros e posterior monitoramento dos mesmos. Estas sugestões viriam a aperfeiçoar um balanço hídrico mais consistente do Sistema Bonfim e Lagoa do Pium, face à importância destes para a Adutora Agreste-Trairi-Potengi e Pium-Parnamirim, respectivamente.

\section{REFERÊNCIAS}

COSTA, W.D. Estudo da disponibilidade hídrica da Lagoa do Bonfim. Costa Consultoria e Serviços Técnicos e Ambientais. Natal, 1997. 83 p. Secretaria de Recursos Hídricos do Estado do Rio Grande do Norte.

FEITOSA, F.A.C. E MANOEL FILHO. Hidrogeologia - conceitos e aplicações. 2a ed. Fortaleza: CPRM/REFO, LABHID-UFPE, 1997. $391 \mathrm{p}$.

IPT. Estudo hidrogeológico regional detalhado do Estado do Rio Grande do Norte. Instituto de Pesquisas Tecnológicas do Estado de São Paulo S/A. Natal, 1982. 389 p. Secretaria de Indústria e Comércio do Estado do Rio Grande do Norte. . Relatório técnico IPT $\mathrm{n}^{\mathrm{o}}$ 15.795.

LANNA, A. E. Manual do MODHAC Modelo Hidrológico Auto-calibrável, versão 97. Porto Alegre: IPH-Instituto de Pesquisas Hidráulicas/UFRGS, 1997.

LANNA, A. E.; SCHWARZBACH, M. (1989). MODHAC - Modelo Hidrológico Auto-calibrável. Porto Alegre: IPH-Instituto de Pesquisas Hidráulicas/UFRGS, 1989. 55 p. (Recursos Hídricos Publicação n. 21).
LUCENA, L.R.F. Implicação da compartimentação estrutural no Aqüífero Barreiras na área da bacia do Rio PirangiRN. Curitiba, 2005. 151 p. Tese de Doutorado. Universidade Federal do Paraná-UFPR.

LUCENA, L.R.F. E QUEIROZ, M.A. Considerações sobre as influências de uma tectônica cenozóica na pesquisa e prospecção de recursos hídricos - o exemplo do litoral sul de Natal-RN, Brasil. Revista Águas Subterrâneas, ABAS, São Paulo, Vol. 1, n. 15: 81-88, 1996.

LUCENA, L.R.F.; ROSA FILHO, E.F.; BITTENCOURT, A. V. L. A potenciometria do Aqüífero Barreiras no setor oriental da bacia do Rio Pirangi-RN e considerações sobre a relação com mananciais superficiais. Revista Águas Subterrâneas, Curitiba, $N^{\circ} 18$, p. 19-27, 2004.

LUCENA, L.R.F.; ROSA FILHO, E.F.; HINDI, E.C. $\mathbf{O}$ fator estrutural atuante na conexão hidráulica subterrânea entre o sistema lacustre do Bonfim e a bacia do Rio Pirangi, litoral leste do Rio Grande do Norte. Revista Águas Subterrâneas, ABAS, São Paulo, n. 16: 69- 
75, 2002.

SANTOS, N.C.F. E LUCENA, L.R.F. Levantamento batimétrico automatizado das lagoas do Jiqui e Pium, litoral sul de NatalRN: uma alternativa viável na avaliação de reservas hídricas superficiais. In: SIMPÓSIO BRASILEIRO DE RECURSOS HÍDRICOS, XV., 2003, Curitiba. Anais... Curitiba: ABRH, 2003. 1 CD-Rom.

\section{AGRADECIMENTOS}

Os autores agradecem a Companhia de Águas e Esgotos do Rio Grande do Norte-CAERN pelo financiamento da pesquisa que resultou no presente trabalho e a Fundação Norte-Rio-Grandense de Pesquisa e Cultura pela administração do referido projeto. 